\title{
Photodissociation of polycrystalline and amorphous water ice films at 157 and $193 \mathrm{~nm}$
}

\section{AUTHOR(S):}

Yabushita, A; Kanda, D; Kawanaka, N; Kawasaki, M; Ashfold, MNR

\section{CITATION:}

Yabushita, A ... [et al]. Photodissociation of polycrystalline and amorphous water ice films at 157 and 193 nm. JOURNAL OF CHEMICAL PHYSICS 2006, 125(13): 133406.

\section{ISSUE DATE:}

2006-10-07

URL:

http://hdl.handle.net/2433/39773

\section{RIGHT:}

Copyright 2006 American Institute of Physics. This article may be downloaded for personal use only. Any other use requires prior permission of the author and the American Institute of Physics. 


\title{
Photodissociation of polycrystalline and amorphous water ice films at 157 and $193 \mathrm{~nm}$
}

\author{
Akihiro Yabushita, Daichi Kanda, Noboru Kawanaka, and Masahiro Kawasaki ${ }^{\text {a) }}$ \\ Department of Molecular Engineering, Kyoto University, Kyoto 615-8510, Japan \\ Michael N. R. Ashfold \\ School of Chemistry, University of Bristol, Bristol, BS8 1TS, United Kingdom
}

(Received 17 April 2006; accepted 13 July 2006; published online 3 October 2006)

\begin{abstract}
The photodissociation dynamics of amorphous solid water (ASW) films and polycrystalline ice (PCI) films at a substrate temperature of $100 \mathrm{~K}$ have been investigated by analyzing the time-of-flight (TOF) mass spectra of photofragment hydrogen atoms at 157 and $193 \mathrm{~nm}$. For PCI films, the TOF spectrum recorded at $157 \mathrm{~nm}$ could be characterized by a combination of three different (fast, medium, and slow) Maxwell-Boltzmann energy distributions, while that measured at $193 \mathrm{~nm}$ can be fitted in terms of solely a fast component. For ASW films, the TOF spectra measured at 157 and $193 \mathrm{~nm}$ were both dominated by the slow component, indicating that the photofragment $\mathrm{H}$ atoms are accommodated to the substrate temperature by collisions. $\mathrm{H}$ atom formation at $193 \mathrm{~nm}$ is attributed to the photodissociation of water species on the ice surface, while at $157 \mathrm{~nm}$ it is ascribable to a mixture of surface and bulk photodissociations. Atmospheric implications in the high latitude mesopause region of the Earth are discussed. (C) 2006 American Institute of Physics. [DOI: $10.1063 / 1.2335840]$
\end{abstract}

\section{INTRODUCTION}

Smaller solar system bodies in space, such as comets, contain a significant fraction of icy materials. Icy particles are also present in planetary atmospheres and play an important role in determining the climate and the environmental conditions on Earth. Water ice is by far the most abundant condensed-phase species in our universe. Because of the interest in photodissociation dynamics of condensed matters in the fields of astrophysics ${ }^{1,2}$ and atmospheric chemistry, ${ }^{3,4}$ a number of studies have been performed on the photochemistry of water ice. Most of these studies reported formation of hydrogen molecules from ice bulk via secondary photochemical reactions after irradiation with vacuum ultraviolet light. ${ }^{1,5,6}$ Formation of hydrogen molecules from ice photolysis at Lyman- $\alpha$ is considered an important source of $\mathrm{H}_{2}$ in the universe. The following reactions are important candidates for the formation of hydrogen molecules from solid water surfaces at low temperature: ${ }^{1}$

$$
\begin{array}{lr} 
& \Delta H_{\text {vapor }} \\
\mathrm{H}_{2} \mathrm{O} \rightarrow \mathrm{H}+\mathrm{OH}, & 5.1 \mathrm{eV}, \\
\mathrm{H}+\mathrm{H}_{2} \mathrm{O} \rightarrow \mathrm{H}_{2}+\mathrm{OH}, \quad-0.6 \mathrm{eV} .
\end{array}
$$

Hydrogen atoms produced in the bulk phase with sufficiently large energy, or on the ice surface, can react with water molecules to produce $\mathrm{H}_{2}$ via reaction (2). The quantum yield for forming molecular hydrogen from water ice photolysis at

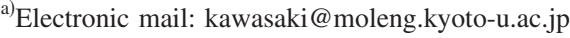

$126 \mathrm{~nm}$ was reported to be $0.01-0.02 .{ }^{1}$ By way of comparison, the corresponding quantum yields following photolysis of aqueous water at 125 and $157 \mathrm{~nm}$ have been reported as, respectively, 1.0 and $0.6^{7}$ Clearly, the $\mathrm{H}_{2}$ quantum yield from reaction (2) is very sensitive to molecular free motion of water in the condensed phase. The photodesorption dynamics of water ice has been studied at 193 and $248 \mathrm{~nm}$ on a $\operatorname{Pd}(111)$ crystal surface, at incident fluences of $5 \mathrm{~mJ} \mathrm{~cm}{ }^{-2}$ pulse $\mathrm{s}^{-1}$. Transient attachment of photoexcited substrate electrons was deduced to occur in the water bilayer immediately adjacent to the metal substrate surface, ${ }^{8,9}$ but only intact $\mathrm{H}_{2} \mathrm{O}$ molecules and no $\mathrm{H}$ or $\mathrm{OH}$ fragments were identified amongst the desorption products.

An ice film absorbs light at $\lambda<160 \mathrm{~nm}$ in the bulk phase. Photodissociation studies involving thick ice films were reported by Nishi et al. ${ }^{10}$ Their essential finding was a very weak $\mathrm{H}$ atom signal following excitation at $193 \mathrm{~nm}$ with a highly focused laser beam $\left(0.5 \mathrm{~J} \mathrm{~cm}^{-2}\right.$ pulse $\left.^{-1}\right)$ via a two-photon process. Yabushita et al. ${ }^{11}$ have reported twophoton induced $\mathrm{H}$ atom production from water films at $248 \mathrm{~nm}$ also (photon density of $2 \mathrm{~mJ} \mathrm{~cm}^{-2}$ pulse $^{-1}$ ), as well as studies of the photodissociation dynamics of dimer-like water molecules on ice surfaces at $193 \mathrm{~nm}$. Investigations of $\mathrm{H}$ atom production from ice surfaces are still very limited, and the search for additional insights is both worthwhile and necessary given the unique reaction environment offered by ice surfaces and bulk phases. ${ }^{12}$ In this study, we report similarities and differences in the dynamics of $\mathrm{H}$ atom formation from the surface and bulk phases of polycrystalline and amorphous water ice films at 157 and $193 \mathrm{~nm}$. 


\section{EXPERIMENT}

\section{A. Time-of-flight apparatus and preparation of ice films}

The time-of-flight apparatus used in the present study has been reported previously. ${ }^{13} \mathrm{~A}$ vacuum chamber was evacuated to a base pressure of $10^{-8}$ Torr using two turbomolecular pumps in tandem (Mitsubishi Heavy Industry, 800 and $50 \mathrm{~L} \mathrm{~s}^{-1}$ ). An optically flat sapphire substrate, sputter coated with a thin film of $\mathrm{Au}$, was supported in the center of the chamber by a liquid-nitrogen-cooled manipulator connected to an $X-Y-Z$ stage. ${ }^{14}$ The temperature of the substrate was controlled to within $1 \mathrm{~K}$. The controller was composed of an alumel-chromel resistance thermometer with cooling, by liquid nitrogen, and heating from a $0.35 \mathrm{~mm}$ diameter tantalum filament attached to the substrate. To prepare the ice surface, $\mathrm{H}_{2} \mathrm{O}$ was injected for $1 \mathrm{~h}$ onto the cooled substrate at $100 \mathrm{~K}$ by a pulsed nozzle (General Valve) at a rate of $10 \mathrm{~Hz}$, at a $45^{\circ}$ incidence angle, and at 20 Torr stagnation pressure of water vapor. This way, an amorphous solid water (ASW) film to a depth of around $600 \mathrm{ML}$ was prepared. ${ }^{15}$ Polycrystalline ice (PCI) films were prepared with the background deposition of water vapor at $130 \mathrm{~K}$ for $60 \mathrm{~min}$ and then maintained at this temperature for a further $30 \mathrm{~min}$ for annealing purposes. Unfocused incident laser radiation of 157 and $193 \mathrm{~nm}$ was steered towards the ice film for photolysis. The $193 \mathrm{~nm}$ laser light (Lambda Physik, COMPex, $\mathrm{ArF}$ ) was directed onto the ice film using an aluminum mirror and a prism resulting in an incident fluence of $0.5 \mathrm{~mJ} \mathrm{~cm}^{-2}$ pulse ${ }^{-1}$, while the $157 \mathrm{~nm}$ photolysis beam (Lambda Physik, OPTexPro, $\mathrm{F}_{2}$ ) was incident directly on the ice surface (fluence $<1 \mathrm{~mJ} \mathrm{~cm}^{-2}$ pulse $^{-1}$ ). Neutral $\mathrm{H}$ atom photofragments were subsequently ionized at a distance of $3 \mathrm{~mm}$ from the substrate surface by $[2+1]$ resonance enhanced multiphoton ionization (REMPI) on the $\mathrm{H}(2 s \leftarrow 1 s)$ transition and collected with a small time-of-flight (TOF) mass spectrometer aligned perpendicular to the ice surface. ${ }^{11}$ The requisite radiation at wavelengths $\sim 243.135 \mathrm{~nm}$ was produced by a Nd:YAG (yttrium aluminum garnet) pumped dye laser (Lambda Physik, SCANmate) using Coumarin 480 dye, followed by subsequent frequency doubling with a beta barium borate (BBO) crystal. The fundamental of the dye laser was separated from the probe beam by a prism and the REMPI beam was focused directly above the substrate with a $20 \mathrm{~cm}$ focal length lens set in the vacuum chamber. The delay, $t$, of the REMPI laser pulse with respect to the photolysis beam pulse was varied with a programed time delay generator (Stanford Research) so as to allow investigation of flight times of the photofragment hydrogen atoms.

\section{B. Simulation of $\mathrm{H}$ atom time-of-flight spectra}

The TOF spectra were fitted with $S\left(t, T_{1}, T_{2}, T_{3}\right)$, consisting of three flux weighted Maxwell-Boltzmann (MB) distributions $P_{\mathrm{MB}}\left(E_{t}, T_{\text {trans }}\right)$, defined by translational temperatures $T_{i}$ and coefficients, $a_{i}$,

$$
\begin{aligned}
S\left(a_{i}, t, T_{1}, T_{2}, T_{3}\right)= & a_{1} S_{\mathrm{MB}}\left(t, T_{1}\right)+a_{2} S_{\mathrm{MB}}\left(t, T_{2}\right) \\
& +a_{3} S_{\mathrm{MB}}\left(t, T_{3}\right),
\end{aligned}
$$

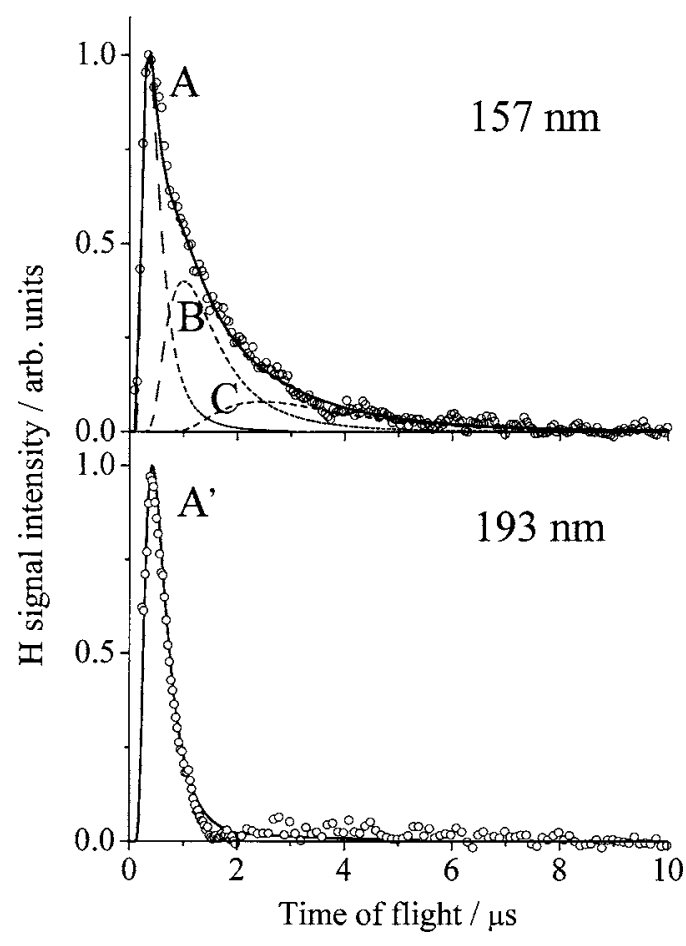

FIG. 1. Time-of-flight spectra of $\mathrm{H}$ atoms from photodissociation of a polycrystalline ice film at 157 and $193 \mathrm{~nm}$ (open circles). The solid lines are fits to the data derived assuming three Maxwell-Boltzmann distributions at $157 \mathrm{~nm}$, with $T=4750 \mathrm{~K}$ for $A, 625 \mathrm{~K}$ for $B$, and $110 \mathrm{~K}$ for $C$ (upper trace, shown by the dashed lines), and one distribution at $193 \mathrm{~nm}$, with $T$ $=2400 \mathrm{~K}\left(A^{\prime}\right.$, lower trace). Relative populations are listed in Table I.

$$
\begin{aligned}
& S_{\mathrm{MB}}(t, r)=r^{3} t^{-4} \exp \left[-m r^{2} /\left(2 k_{\mathrm{B}} T_{\text {trans }} t^{2}\right)\right], \\
& P_{\mathrm{MB}}\left(E_{t}, T_{\text {trans }}\right)=\left(k_{\mathrm{B}} T_{\text {trans }}\right)^{-2} E_{t} \exp \left[-E_{t} /\left(k_{\mathrm{B}} T_{\text {trans }}\right)\right],
\end{aligned}
$$

where $r$ is a flight length for the photofragment. $P_{\mathrm{MB}}\left(E_{t}, T_{\text {trans }}\right)$ is characterized by the average translational energy $\left\langle E_{t}\right\rangle=2 k_{\mathrm{B}} T_{\text {trans }}$, where $k_{B}$ is the Boltzmann constant. Conversion from the energy distribution to the TOF distribution was performed using the Jacobian given by Zimmerman and Ho. ${ }^{16}$ Since the ice films employed in these experiments are of amorphous and polycrystalline surface morphologies, the angular distribution of the $\mathrm{H}$ atoms were all assumed to be isotropic. The accuracy of the conversion procedure was confirmed experimentally by changing the flight length from 3 to $5 \mathrm{~mm}$ with the aid of the $X-Y-Z$ stage. The details of the simulation of the TOF spectra were described in our previous paper. $^{13}$

\section{RESULTS}

\section{A. Photodissociation of polycrystalline ice films}

Figure 1 shows typical TOF spectra of $\mathrm{H}$ atoms from photodissociation of PCI films at $100 \mathrm{~K}$. Each spectrum is the sum of several spectra, measured at different Doppler shifted wavelengths around that required for $\mathrm{H}$ atom REMPI detection via the $2 s \leftarrow 1 s$ transition. The TOF spectrum obtained at $193 \mathrm{~nm}$ is well described by a single, fast component $\left(A^{\prime}\right)$ with $T_{\text {trans }}=2400 \pm 100 \mathrm{~K}\left(\left\langle E_{t}\right\rangle=0.31 \pm 0.01 \mathrm{eV}\right)$, to be compared with an excess energy of $1.3 \mathrm{eV}$ for the (gas phase) photodissociation process (1) at $193 \mathrm{~nm}$. As described 


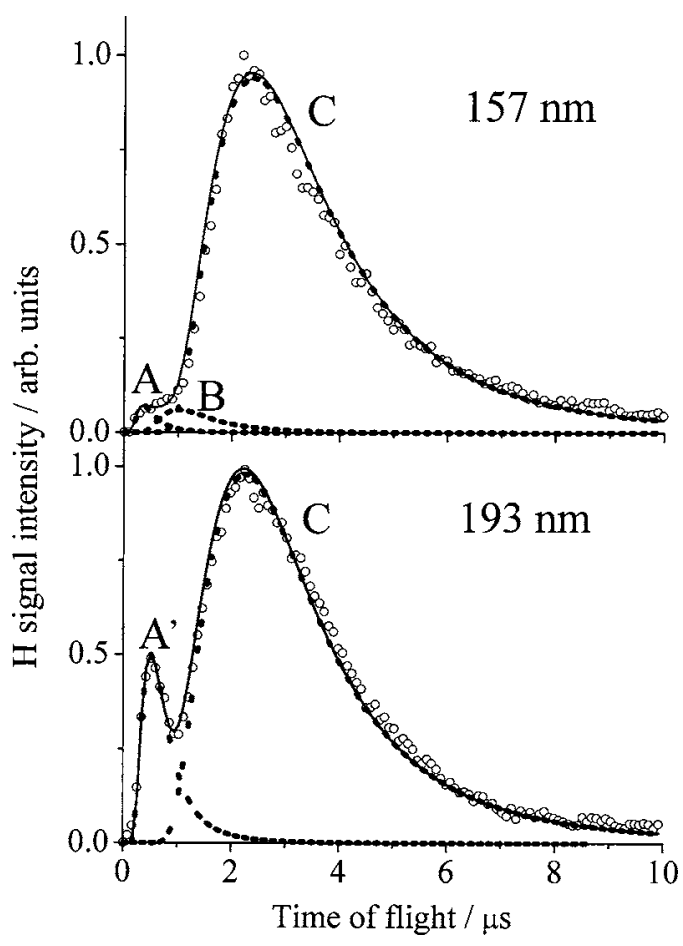

FIG. 2. Time-of-flight spectra of $\mathrm{H}$ atoms from photodissociation of amorphous solid water films at 157 and $193 \mathrm{~nm}$. The translational temperatures of the various contributory components are the same as in Fig. 1.

below, photoabsorption at $193 \mathrm{~nm}$ is attributed solely to the surface water species; the translational temperature of the resulting $\mathrm{H}$ atoms is much higher than the substrate temperature. Conversely, the TOF spectrum measured at $157 \mathrm{~nm}$ was well reproduced by summing three different MB distributions because $\mathrm{H}$ atoms are produced both from surface species and from inner layers within the ice films. Hence, we analyzed the TOF spectrum with a high-temperature component, a surface accommodated component, and a residual component, i.e., a high-temperature fast component $(A)$ with $T_{\text {trans }}=4750 \pm 250 \mathrm{~K} \quad\left(\left\langle E_{t}\right\rangle=0.61 \pm 0.03 \mathrm{eV}\right) \quad$ contributing $41 \% \pm 3 \%$; a residual middle component $(B)$ with $T_{\text {trans }}$ $=625 \pm 25 \mathrm{~K} \quad\left(\left\langle E_{t}\right\rangle=0.081 \pm 0.003 \mathrm{eV}\right) \quad$ contributing $44 \% \pm 4 \%$; and a surface accommodated slow component (C) with $T_{\text {trans }}=110 \pm 10 \mathrm{~K}\left(\left\langle E_{t}\right\rangle=0.014 \pm 0.001 \mathrm{eV}\right)$ contributing $15 \% \pm 5 \%$. By way of comparison, the excess energy associated with photodissociation process (1) at $157 \mathrm{~nm}$ is $2.8 \mathrm{eV}$ (based on the thermodynamics of the gas phase dissociation).

\section{B. Photodissociation of amorphous solid water films}

Figure 2 shows typical TOF spectra of $\mathrm{H}$ atoms released following photoexcitation of ASW films at $100 \mathrm{~K}$. Spectra recorded at 157 and $193 \mathrm{~nm}$ are similar to each other, but the relative contributions of each component vary. Three MB components are required to fit the TOF spectrum measured at $157 \mathrm{~nm}: A$ with $T_{\text {trans }}=4750 \pm 250 \mathrm{~K}$ (contributing $3 \% \pm 2 \%$ ), $B$ with $T_{\text {trans }}=625 \pm 25 \mathrm{~K}(5 \% \pm 2 \%)$, and $C$ with $T_{\text {trans }}$ $=110 \pm 10 \mathrm{~K}(92 \% \pm 4 \%)$. The TOF spectrum recorded at $193 \mathrm{~nm}$ is also dominated by component $C$ ( $T_{\text {trans }}$ $=110 \pm 10 \mathrm{~K}$, contributing $85 \% \pm 3 \%$ ), but also includes some $A^{\prime}$ component with $T_{\text {trans }}=2400 \pm 100 \mathrm{~K}(15 \% \pm 3 \%)$. Table I summarizes the translational temperatures and contributions of each component.

\section{DISCUSSION}

\section{A. Photoabsorption of water ice film}

Water is almost transparent, in either vapor or ice form, for near-UV irradiation at $\lambda=200 \mathrm{~nm} .{ }^{17}$ The absorption cross section, $\sigma(200 \mathrm{~nm})$, is as small as $10^{-23} \mathrm{~cm}^{2}$ in the gas phase. $^{18}$ The previously reported photodissociation of gaseous $\mathrm{H}_{2} \mathrm{O}$ at $193 \mathrm{~nm}$ was assisted by vibrational excitation of the parent water molecule. ${ }^{19}$ Ice exhibits a region of weak and continuous absorption at $\lambda \sim 195 \mathrm{~nm}$, which may be attributable to surface water molecules. ${ }^{20,21}$ The electronic absorption spectra of cyclic water clusters $\left(\mathrm{H}_{2} \mathrm{O}\right)_{n}$ are calculated to be blueshifted relative to that of the water monomer. ${ }^{22-24}$ Among these clusters, $\left(\mathrm{H}_{2} \mathrm{O}\right)_{6}$ is considered as a model structure for a crystalline water film. ${ }^{25} \mathrm{Ab}$ initio calculations of a water molecule on a model ice surface, $\left(\mathrm{H}_{2} \mathrm{O}\right)_{6+1}$, predict that this branched cluster will exhibit absorption at $\lambda \sim 200 \mathrm{~nm}$, as a result of electronic promotion from the $1 b_{1}$ molecular orbital to a mixed $3 s$ (Rydberg) $/ 4 a_{1}$ (antibonding valence) orbital within a dimer-like surface structure. ${ }^{11}$ Two recent three-dimensional quantum dynamics studies of the gas phase dimer both predict that its spectrum is broader than that of the monomer, but predict rather different blueshifts relative to the monomer

TABLE I. Average translational temperature of $\mathrm{H}$ atoms from photolysis of polycrystalline or amorphous solid water films at 157 and $193 \mathrm{~nm}$.

\begin{tabular}{|c|c|c|c|c|c|c|c|}
\hline \multirow{3}{*}{$\begin{array}{l}\text { Dissoclation } \\
\text { wavelength } \\
\quad(\mathrm{nm})\end{array}$} & \multirow[b]{3}{*}{ Ice film } & \multicolumn{6}{|c|}{ Maxwell-Boltzmann component } \\
\hline & & \multicolumn{2}{|c|}{$A$ and $A^{\prime}$} & \multicolumn{2}{|r|}{$B$} & \multicolumn{2}{|r|}{ C } \\
\hline & & $T(\mathrm{~K})$ & Contribution (\%) & $T(\mathrm{~K})$ & Contribution (\%) & $T(\mathrm{~K})$ & Contribution (\%) \\
\hline \multirow[t]{2}{*}{157} & $\mathrm{ASW}^{\mathrm{a}}$ & $4750 \pm 250$ & $3 \pm 2$ & $625 \pm 25$ & $5 \pm 2$ & $110 \pm 10$ & $92 \pm 4$ \\
\hline & $\mathrm{PC}^{\mathrm{b}}$ & $4750 \pm 250$ & $41 \pm 3$ & $625 \pm 25$ & $44 \pm 4$ & $110 \pm 10$ & $15 \pm 5$ \\
\hline \multirow[t]{2}{*}{193} & $\mathrm{ASW}^{\mathrm{a}}$ & $2400 \pm 100$ & $15 \pm 3$ & $\cdots$ & $\cdots$ & $110 \pm 10$ & $85 \pm 3$ \\
\hline & $\mathrm{PC}^{\mathrm{b}}$ & $2400 \pm 100$ & 100 & $\ldots$ & $\ldots$ & $\ldots$ & $\ldots$ \\
\hline
\end{tabular}

${ }^{\mathrm{a} A S W}=$ amorphous solid water film.

${ }^{\mathrm{b}} \mathrm{PCI}=$ polycrystalline ice. 
band-ranging from negligible ${ }^{26}$ to $\sim 0.2 \mathrm{eV} .^{27}$ The latter calculations also failed to reproduce the previously predicted "red tail" to the water dimer absorption at $\sim 200 \mathrm{~nm}$ even following excitation of one or two quanta of the dimer stretch vibration. ${ }^{22}$ It seems unlikely that triplet states of water clusters contribute to the red end of the electronic absorption spectrum for the following reason. Studies of the gas phase water dimer identify contributions to the singlet-triplet transition intensity arising as a result of mixing between the $1{ }^{3} B_{1}$ state with the $1{ }^{1} A_{1}$ electronic ground state, and from mixing of both the $1{ }^{1} A_{1}$ and $2{ }^{1} A_{1}$ states with the $1{ }^{3} B_{1}$ state. ${ }^{27}$ However, if the $1{ }^{3} B_{1}$ state made any contribution in the $193 \mathrm{~nm}$ photodissociation of PCI, then both the fast TOF peak from the surface species and the slow signal from the inner water bilayer should be observed as will be discussed below. In practice, the TOF spectrum from PCI at $193 \mathrm{~nm}$ showed just a single, fast $\mathrm{H}$ atom peak.

For condensed water, reflectivity spectra due to electron excitation in amorphous and crystalline ices have been measured at $80 \mathrm{~K}$ across the energy range of $7-28 \mathrm{eV} .{ }^{17}$ Analysis identified excitations at $\sim 8.6, \sim 10.4$, and $\sim 14.5 \mathrm{eV}$. The $8.6 \mathrm{eV}$ excitation was assigned to the $3 s / 4 a_{1}\left({ }^{1,3} B_{1}\right) \leftarrow 1 b_{1}$ transition.

\section{B. Origins of the present time-of-flight spectra 1. Photodissociation of polycrystalline ice films at 157 and $193 \mathrm{~nm}$}

We attribute the MB components $A$ (at $157 \mathrm{~nm}$ ) and $A^{\prime}$ (at $193 \mathrm{~nm}$ ) in Fig. 1 to the same origin, namely, photodissociation within the uppermost $\mathrm{H}_{2} \mathrm{O}$ layer of the ice film, with the differences in the translational energy distributions reflecting the difference in the excess energies accompanying the respective photodissociation processes. We note that, for both the $A$ and $A^{\prime}$ components, about one quarter of the excess energy is released in the form of $\mathrm{H}$ atom translational energy. Since the bulk ice film absorbs at $157 \mathrm{~nm}$, it is reasonable to suggest that $\mathrm{H}$ atoms characterized by the $\mathrm{MB}$ components $B$ and $C$ in the TOF spectra measured at $157 \mathrm{~nm}$ were generated deeper within the ice sample and subsequently desorbed from the film.

\section{Photodissociation of amorphous solid water films at 157 and $193 \mathrm{~nm}$}

The relatively greater contribution made by component $C$ to the spectrum recorded at $157 \mathrm{~nm}$ in Fig. 2 can be understood by recognizing that, at this wavelength, $\mathrm{H}$ atoms will be produced in the bulk phase as well as from exposed surfaces within the porous ASW film; all such $\mathrm{H}$ atoms are likely to accommodate to the substrate temperature by collisions within the pore structure before desorbing into the vacuum. A schematic diagram illustrating the various $\mathrm{H}$ atom formation processes from the photodissociation of the ASW films is shown in Fig. 3.

\section{Photodissociation dynamics of ice films 1. Photodissociation at $193 \mathrm{~nm}$}

Comparing the PCI and ASW results following excitation at $193 \mathrm{~nm}$ (Table I) highlights the influence of the sur-

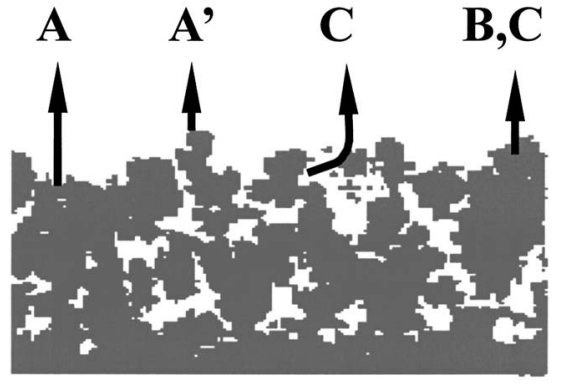

FIG. 3. Schematic diagram of $\mathrm{H}$ atom formation processes from an amorphous ice film. $A, B, C$, and $A^{\prime}$ represent the Maxwell-Boltzmann components listed in Table I.

face morphology on the resulting $\mathrm{H}$ atom translational energy distributions. Only component $A^{\prime}$ was observed in the case of PCI films, whereas, for ASW films, component $C$ is the dominant $(85 \% \pm 3 \%)$ contributor to the observed TOF distribution of $\mathrm{H}$ atom. The dominance of component $C$ in the case of ASW films is attributable to relaxation of the nascent $\mathrm{H}$ atom velocities as a result of collisions with internal surfaces within the porous amorphous ice structure, as shown schematically in Fig. 3.

In previous experiments at $193 \mathrm{~nm}$, we have shown that the fast component $A^{\prime}$ from the PCI film arises from onephoton dissociation of dimer-like water molecules on the outermost layer of the ice film. ${ }^{11}$ It could exhibit weak absorption at $\lambda \sim 200 \mathrm{~nm}$ given its similarity with the deduced chromophore in the branched form of the $\left(\mathrm{H}_{2} \mathrm{O}\right)_{6+1}$ water cluster. ${ }^{11}$ Kimmel and Orlando reported threshold energies of 6.5-7.0 eV for desorption of $\mathrm{D}$ atoms following electronbeam irradiation on thin films of amorphous $\mathrm{D}_{2} \mathrm{O}$ ice, ${ }^{28} \mathrm{im}$ plying that a dissociative excited state of $\mathrm{D}_{2} \mathrm{O}$ is accessible at this energy. Their TOF spectra of D atoms were decomposed into three components. One, fast, component was attributed to $\mathrm{D}$ atoms ejected directly from the surface without interacting with surrounding molecules, while the other two were associated with atoms that had accommodated to the surface temperature prior to desorption. Clearly, their findings and conclusions are in good agreement with the present TOF results, suggesting that the same electronic excitation and dissociation dynamics occur as a result of both photoexcitation and electron bombardment.

\section{Photodissociation at $157 \mathbf{n m}$}

In a recent publication, ${ }^{29}$ molecular dynamics calculations have been performed using analytical potentials to simulate a crystalline ice surface consisting of eight-bilayers (16 ML) of $60 \mathrm{H}_{2} \mathrm{O}$ molecules each and an amorphous ice surface consisting of the six-top monolayers containing 180 $\mathrm{H}_{2} \mathrm{O}$ molecules at $10 \mathrm{~K}$. This work shows that, upon photodissociation to give $\mathrm{H}+\mathrm{OH}$, the vibrational energy distribution of the remaining $\mathrm{OH}$ had a maximum population at $\nu$ $=0$, implying that most of the energy in excess of that required for bond fission is released as $\mathrm{H}$ atom kinetic energy. As the depth of the molecule undergoing photodissociation increased, the fraction of $\mathrm{H}$ atoms that succeed in escaping from the surface was calculated to decline near quadratically; most $\mathrm{H}$ atoms arising from photolysis of such embedded 
molecules remained trapped in the network (or underwent other processes). The desorption probability of $\mathrm{H}$ atoms formed in association with $\mathrm{OH}$ partners that remained trapped is higher for the first three monolayers in the case of amorphous ice $(89 \%, 75 \%$, and $55 \%$ ) than for the corresponding layers in crystalline ice $(71 \%, 57 \%$, and $27 \%)$ but the differences become less pronounced for the next three monolayers: $30 \%, 22 \%$, and $12 \%$ for amorphous ice, cf. $22 \%, 15 \%$, and $11 \%$ for crystalline ice. The calculated probability that the $\mathrm{H}$ and $\mathrm{OH}$ products arising from a single photolysis event both desorb is much lower (7\% and 2\% for the first and second monolayers, respectively). Given these results, the discussion that follows is based on the reasonable assumption that $\mathrm{H}$ atoms produced from the photodissociation of crystalline ice films at $157 \mathrm{~nm}$ originate from just the uppermost six monolayers. From the structure of crystalline ice film, component $A$ must come from the first monolayer. ${ }^{30}$ In the present experiments involving PCI films, we attribute component $A$ to photodissociation of molecules on the vacuum side in the first bilayer, i.e., the first monolayer. The fraction of the total $\mathrm{H}$ atom yields calculated to arise from this layer is $(71+7) /(71+57+27+22+15+11+7+2)=37 \%$ in very fair agreement with that measured experimentally (component $A=41 \% \pm 3 \%$ ). Similarly, the calculated contribution from the second and third monolayers, $41 \%$, matches well with the experimentally measured contribution ( $44 \% \pm 4 \%)$ of component $B$, while the calculated contribution from the fourth, fifth, and sixth monolayers, $22 \%$, accords with the experimentally measured contribution (15\%) of component $C$. Thus it is tempting to associate component $B$ with photodissociation of water molecules in the second and third monolayers, and component $C$ with dissociation of molecules in the deeper monolayers.

It is instructive to compare the present results with those from photodissociation studies of single $\mathrm{HBr}$ and $\mathrm{HI}$ molecules adsorbed on the surface of (and in) large rare gas clusters by Baumfalk et al. ${ }^{31}$ All systems studied exhibited both fast $\mathrm{H}$ atoms, with no energy loss, indicative of direct exit from a molecule on the cluster surface, and atoms with near-zero energy, indicative of complete caging. In the case of porous films, temperature-programed desorption spectroscopy has revealed two signatures of porosity: a reduction in the desorption rate with increasing film thickness, and a change in peak shape. ${ }^{32}$ Such observations have been explained in terms of fast diffusion into the ASW pore structure, using a simple one-dimensional diffusion model, and by a change in binding energy statistics with increasing total effective surface area. $\mathrm{D}_{2}$ desorption kinetics on nonporous ASW films have also been investigated. ${ }^{32}$ Both the porosity and the number of highly coordinated binding sites were seen to decrease with increasing anneal temperature, indicative of ASW restructuring and pore collapse. These results suggested that grain morphology, rather than the detailed chemical nature of the grain surface, was the most important in determining the energy content of the $\mathrm{D}_{2}$ released from the grain.

\section{D. $\mathrm{H}$ atom translational energies}

Kinetic energy distributions of desorbing $\mathrm{H}$ atoms following photodissociation of the first bilayer in crystalline and amorphous ice films at the first vacuum UV band at $8.6 \mathrm{eV}$ have been calculated by Andersson et al., ${ }^{29}$ using a classical molecular dynamics approach. The average $\mathrm{H}$ atom kinetic energies obtained in these calculations correspond to about half the average excess energy. As described above, our experimental results for the $A$ and $A^{\prime}$ components (at 157 and $193 \mathrm{~nm}$ ) indicate that only about one quarter of the excess energy is released as $\mathrm{H}$ atom translation. The calculated kinetic energy release is thus about twice the experimental values. All water molecules in the molecular dynamics calculations were treated as rigid rotors, apart from the one molecule chosen to be dissociated. The three atoms in this dissociating molecule were allowed to move without dynamical constraints. The rigidity of all other molecules, however, excludes the possibility of energy transfer to intramolecular vibrational modes and bond breaking reactions in $\mathrm{H}_{2} \mathrm{O}$ molecules other than the one chosen for the primary photodissociation event. A more realistic model might allow the water molecules to move, and energy transfer to intramolecular vibrational modes. Thus it is not unreasonable to suppose that collisions between $\mathrm{H}$ atoms and other water molecules would result in more efficient relaxation of the translational energies of the desorbing $\mathrm{H}$ atoms than suggested by the molecular dynamics calculations reported to date.

\section{E. Consideration of possible contributions from ion processes}

Simpson et $a l^{33}$ have investigated the electronstimulated desorption (ESD) of $\mathrm{D}^{-}$anions from ice films, followed by the reaction of $\mathrm{D}^{-}+\mathrm{D}_{2} \mathrm{O} \rightarrow \mathrm{D}_{2}+\mathrm{OD}^{-}$. Their observed anion signals show an energetic onset of $\sim 5.5 \mathrm{eV}$ and peak at $\sim 7 \mathrm{eV}$. This feature is assigned in terms of electronic transition to the ${ }^{2} B_{1}$ dissociative electron attachment resonance of water in the ice film. Since the $\mathrm{H}^{+}$ion formation threshold is $\sim 21 \mathrm{eV}$, we can rule out $\mathrm{H}^{+}+\mathrm{OH}^{-}$recombination forming a dissociative excited state of water as a possible source of neutral $\mathrm{H}$ atoms or $\mathrm{H}_{2}$ molecules in the present photolysis experiments.

Ions formed during electron irradiation of water ice films can be neutralized, reactively scattered, or attenuated in other ways through collisions with the walls of pores. ${ }^{34}$ For example, neutral products observed during low energy electron bombardment of ice films at $55 \mathrm{~K}$ include $\mathrm{H}, \mathrm{H}_{2}, \mathrm{O}\left({ }^{3} P,{ }^{1} D\right)$, $\mathrm{O}_{2}, \mathrm{H}_{2} \mathrm{O}$, and $\mathrm{H}_{2} \mathrm{O}_{2}{ }^{28,35}$ All of these products, which are revealed in the post-irradiation temperature-programed desorption spectra (at temperatures up to $120 \mathrm{~K}$ for hydrogen and $160 \mathrm{~K}$ for oxygen), are deduced to originate within the porous structures in the ice films. ${ }^{35}$ Similar results have been reported following excitation with $1.5 \mathrm{MeV} \mathrm{Ne}{ }^{+}$ions. ${ }^{36}$ Clearly, the porosity of the film could have a major influence the formation of neutral species by ion-initiated processes. 


\section{F. Atmospheric implications in the stratosphere and mesosphere}

The water vapor mixing ratio in the middle atmosphere of the Earth is maintained to be $\sim 1-10$ ppmv. Water vapor is considered to be the most important source of $\mathrm{H}$ atoms in this region, formed mainly by photodissociation of water monomers by solar Lyman- $\alpha$ radiation. These serve to initiate the $\mathrm{HO}_{x}$ cycle and thereby decrease the $\mathrm{O}_{3}$ mixing ratio. ${ }^{37}$ Ice particles are formed in the high latitude mesosphere between 80 and $90 \mathrm{~km}$ during summer, when temperature fall below $150 \mathrm{~K}$, and recognized as noctilucent clouds (NLCs).$^{38}$ Although much work has been directed at understanding cloud formation processes and the properties of ice aerosol particles, little attention has been paid to the possible role that ice particles may play in the neutral chemistry of the upper mesosphere. Recently, this issue has begun to be addressed quantitatively through laboratory and modeling studies. ${ }^{439,40}$ Murray and Plane have examined the impact of mesospheric ice particles on the odd oxygen and hydrogen chemistry of the high latitude summer mesosphere and have proposed a mechanism whereby direct photolysis of ice particles produces odd hydrogen species in the gas phase.

With regard to the atmospheric implications of the present results, we now estimate the relative contributions to $\mathrm{H}$ atom formation in the high latitude mesopause region made by solar Lyman- $\alpha$ photolysis of ice particles and of water vapor. In both cases, the $\mathrm{H}$ atom yield, $N$, can be expressed as

$$
N=\phi I(121.6 \mathrm{~nm})\{1-\exp (-\sigma n)\},
$$

where $\sigma$ is the relevant absorption cross section at the Lyman- $\alpha$ wavelength, $n$ is the number density of the precursor of interest, and $I$ the solar flux. ${ }^{41}$ For water vapor, the photodissociation quantum yield $\phi_{\text {vapor }}$ is unity. The absolute quantum yield for $\mathrm{H}$ atom production from an ice film $\phi_{\text {ice }}$ could not be measured in the present experiment. The yield is thus estimated from the results of the classical dynamics calculations of the photodissociation of water in crystalline ice. ${ }^{29}$ As outlined above, the overall probability of $\mathrm{H}$ atom desorption for the first six monolayers is $\sim 0.35$ [i.e., (71 $+57+27+22+15+11+7+2) / 600]$. $\mathrm{H}$ atoms might escape from yet deeper ice layers, but the calculated decrease in $\mathrm{H}$ atom desorption probability with increasing depth suggests that considering just the first six monolayers is sufficient for the present estimation. Given the ice lattice constant of $0.5 \mathrm{~nm},{ }^{30}$ the fraction of a spherical ice particulate with $r$ $=0.04 \mu \mathrm{m}$ that falls within the first six monolayers is 1 $-(37 / 40)^{3}=0.21$. For a spherical ice particle, the effective intensity of the solar radiation is reduced to a quarter of its original intensity. Thus the effective quantum yield can be estimated to be $0.35 \times 0.21 \times(1 / 4)=0.018$. This value is in fair agreement with the quantum yield (0.01-0.02) for molecular hydrogen formation from ice film at $121.6 \mathrm{~nm}$ via (1) and (2). ${ }^{1}$ At $83 \mathrm{~km}$ altitude, Murray and Plane reported that the density of ice particulates $n=600 \mathrm{~cm}^{-3}$ and that their Mie absorption cross section is $3 \times 10^{-8} \mathrm{~cm}^{2} \mathrm{~cm}^{-3}$ (i.e., total absorption cross section per unit volume of atmosphere). ${ }^{4}$ In the case of water vapor, we assume $\left\langle n_{\text {vapor }}\right\rangle=4 \times 10^{9} \mathrm{~cm}^{-3}$ from the reported mixing ratios $(5-10 \mathrm{ppmv})$ at the corresponding altitude. ${ }^{37,42,43}$ The absorption cross section of water vapor at $121.6 \mathrm{~nm}$ is $\sigma_{\text {vapor }}=1.4 \times 10^{-17} \mathrm{~cm}^{2}$. Thus the relative contributions of ice photodissociation and water vapor photodissociation to $\mathrm{H}$ atom production at an altitude of $83 \mathrm{~km}$ can be estimated as $N($ ice $) / N($ vapor $)=0.018 \times 3$ $\times 10^{-8} /\left(1 \times 1.4 \times 10^{-17} \times 4 \times 10^{9}\right) \sim 0.01$. This estimation neglects the facts that (i) NLC particles are nonspherical and their surface is unlikely to be smooth, ${ }^{44}$ (ii) NLCs have surface areas up to 500 times larger than the geometric surface area of the substrate, ${ }^{45}$ and (iii) the solar flux and the number density are both a function of altitude. A model calculation is needed for a more precise estimate of the contribution from ice photodissociation.

\section{CONCLUSION}

The photodissociation dynamics of surface and bulk ice films have been investigated using 193 and $157 \mathrm{~nm}$ radiations. For PCI films, the $\mathrm{H}$ atom TOF spectrum measured at $157 \mathrm{~nm}$ was characterized by a combination of three Maxwell-Boltzmann energy distributions, represented by translational temperatures (populations): $T_{A}=4750 \pm 250 \mathrm{~K}$ $(41 \% \pm 3 \%), \quad T_{B}=625 \pm 25 \mathrm{~K} \quad(44 \% \pm 4 \%), \quad$ and $T_{C}$ $=110 \pm 10 \mathrm{~K}(15 \% \pm 5 \%)$, respectively, while the TOF spectrum obtained at $193 \mathrm{~nm}$ was characterized solely by $T_{A}$ $=2400 \pm 100 \mathrm{~K}(100 \%)$. For ASW films, the $\mathrm{H}$ atom TOF spectrum recorded at $157 \mathrm{~nm}$ was again characterized using the three components (populations): $T_{A}=4750 \pm 250 \mathrm{~K}$ $(3 \% \pm 2 \%), \quad T_{B}=4750 \pm 250 \mathrm{~K} \quad(5 \% \pm 2 \%), \quad$ and $T_{C}$ $=110 \pm 10 \mathrm{~K}(92 \% \pm 4 \%)$, while the $193 \mathrm{~nm}$ spectrum was composed of $T_{A}=2400 \pm 100 \mathrm{~K} \quad(15 \% \pm 3 \%)$, and $T_{C}$ $=110 \pm 10 \mathrm{~K}(85 \% \pm 3 \%)$. The present results indicate that the source of $\mathrm{H}$ atoms arising following excitation at $193 \mathrm{~nm}$ is photodissociation of surface species on ice films. In contrast, $157 \mathrm{~nm}$ excitation yields $\mathrm{H}$ atoms by photodissociation both of surface species and from the bulk of ice films. $\mathrm{H}$ atoms generated in the bulk ice are accommodated to the surface temperature by collisional relaxation. By comparing TOF spectra obtained following photoexcitation of both amorphous ice and polycrystalline ice samples, we deduce that surface morphology can have a major influence on the eventual $\mathrm{H}$ atom translational energy distributions.

\section{ACKNOWLEDGMENTS}

The authors thank A. Ikeda and D. W. Comerford for stimulating discussion. The award of a Daiwa-Adrian prize facilitated this collaboration between the Japanese and UK research groups.

\footnotetext{
${ }^{1}$ N. Watanabe, T. Horii, and A. Kouchi, Astrophys. J. 541, 772 (2000).

${ }^{2}$ R. E. Johnson and T. I. Quickenden, J. Geophys. Res. 102, 10985 (1997).

${ }^{3}$ P. Klan and I. Holoubek, Chemosphere 46, 1201 (2002).

${ }^{4}$ B. J. Murray and J. M. C. Plane, Atmos. Chem. Phys. 5, 1027 (2005).

${ }^{5}$ M. S. Westley, R. A. Baragiola, R. E. Johnson, and G. A. Baratta, Planet. Space Sci. 43, 1315 (1995).

${ }^{6}$ G. Gilarowski, W. Erley, and H. Ibach, Surf. Sci. 351, 156 (1996).
} 
${ }^{7}$ G. Heit, A. Neuner, P. Y. Saugy, and A. M. Braun, J. Phys. Chem. A 102, 5551 (1998).

${ }^{8}$ M. Wolf, S. Nettesheim, J. M. White, E. Hasselbrink, and G. Ertl, J. Chem. Phys. 94, 4609 (1991).

${ }^{9}$ X.-Y. Zhu, J. M. White, M. Wolf, E. Hasselbrink, and G. Ertl, J. Phys. Chem. 95, 8393 (1991)

${ }^{10}$ N. Nishi, H. Shinohara, and T. Okuyama, J. Chem. Phys. 80, 3898 (1984).

${ }^{11}$ A. Yabushita, Y. Hashikawa, A. Ikeda, M. Kawasaki, and H. Tachikawa, J. Chem. Phys. 120, 5463 (2004).

${ }^{12}$ H. Kang, Acc. Chem. Res. 38, 893 (2005)

${ }^{13}$ A. Yabushita, Y. Inoue, T. Senga, M. Kawasaki, and S. Sato, J. Phys. Chem. B 106, 3151 (2002).

${ }^{14}$ M. Kawasaki, Appl. Surf. Sci. 135, 1159 (1998).

${ }^{15}$ S. Sato, D. Yamaguchi, K. Nakagawa, Y. Inoue, A. Yabushita, and M. Kawasaki, Langmuir 16, 9533 (2000).

${ }^{16}$ F. M. Zimmermann and W. Ho, Surf. Sci. Rep. 22, 127 (1995).

${ }^{17}$ K. Kobayashi, J. Phys. Chem. 87, 4317 (1983).

${ }^{18}$ C.-Y. Chung, E. P. Chew, B.-M. Chen, M. Bahou, and Y.-P. Lee, Nucl. Instrum. Methods Phys. Res. A 467, 1572 (2001).

${ }^{19}$ D. F. Plusquellic, O. Votava, and D. J. Nesbitt, J. Chem. Phys. 107, 6123 (1997).

${ }^{20}$ K. Dressler and O. Schnepp, J. Chem. Phys. 33, 270 (1960).

${ }^{21}$ A. P. Minton, J. Phys. Chem. 75, 1162 (1971).

${ }^{22}$ J. N. Harvey, J. O. Jung, and R. B. Gerber, J. Chem. Phys. 109, 8747 (1998).

${ }^{23}$ Y. Miller, E. Fredj, J. N. Harvey, and R. B. Gerber, J. Phys. Chem. A 108, 4405 (2004)

${ }^{24}$ A. L. Sobolewski and W. Domcke, J. Chem. Phys. 122, 184320 (2005).

${ }^{25}$ J. C. Jiang, J.-C. Chang, B.-C. Wang, S. H. Lin, Y. T. Lee, and H.-C. Chang, Chem. Phys. Lett. 289, 373 (1998).

${ }^{26}$ D. M. Chipman, J. Chem. Phys. 122, 044111 (2005).
${ }^{27}$ L. Valenzano, M. C. van Hemer, and G.-J. Kroes, J. Chem. Phys. 123, 034303 (2005).

${ }^{28}$ G. A. Kimmel and T. M. Orlando, Phys. Rev. Lett. 75, 2606 (1995).

${ }^{29}$ S. Andersson, A. Al-Halabi, G.-J. Kroes, and E. F. van Dishoeck, J. Chem. Phys. 124, 064715 (2006).

${ }^{30}$ N. Materer, U. Starke, A. Barbieri, M. A. Van Hove, G. A. Somorjai, G.-J. Kroes, and C. Minot, Surf. Sci. 381, 190 (1997).

${ }^{31}$ R. Baumfalk, N. H. Nahler, and U. Buck, Faraday Discuss. 118, 247 (2001).

${ }^{32}$ L. Hornekaer, A. Baurichter, V. V. Petrunin, A. C. Luntz, B. D. Kay, and A. Al-Halabi, J. Chem. Phys. 122, 124701 (2005).

${ }^{33}$ W. C. Simpson, L. Parenteau, R. S. Smith, L. Sanche, and T. M. Orlando, Surf. Sci. 390, 86 (1997).

${ }^{34}$ M. T. Sieger and T. M. Orlando, Surf. Sci. 390, 92 (1997).

${ }^{35}$ G. A. Grieves and T. M. Orlando, Surf. Sci. 593, 180 (2005).

${ }^{36}$ R. E. Johnson, P. D. Cooper, T. I. Quickenden, G. A. Grieves, and T. M. Orlando, J. Chem. Phys. 123, 184715 (2005).

${ }^{37}$ I. M. Vardavas, J. H. Carver, and F. W. Taylor, Ann. Geophys. 16, 189 (1998).

${ }^{38}$ G. E. Thomas, Rev. Geophys. 29, 553 (1991).

${ }^{39}$ B. J. Murray and J. M. C. Plane, Adv. Space Res. 31, 2075 (2003).

${ }^{40}$ B. J. Murray and J. M. C. Plane, Phys. Chem. Chem. Phys. 5, 4129 (2003).

${ }^{41}$ G. P. Brasseur, J. J. Orlando, and G. S. Tyndall, Atmospheric Chemistry and Global Change (Oxford University Press, New York, 1999).

${ }^{42}$ P. J. Espy and H. Jutt, J. Atmos. Sol.-Terr. Phys. 64, 1823 (2002).

${ }^{43}$ J. M. Wallace and P. V. Hobbs, Atmospheric Science (Academic, New York, 1977)

${ }^{44}$ G. Baumgarten, K. H. Fricke, and G. T. von Cossart, Geophys. Res. Lett. 29, 1630 (2002).

${ }^{45}$ F. J. Lübken, K. H. Fricke, and M. Langer, J. Geophys. Res. 101, 9489 (1996). 